\title{
DISTRIBUTION AND CURRENT STATUS OF NATURAL ENEMIES OF PAROPSIS CHARYBDIS IN NEW ZEALAND
}

\author{
T.J. MURRAY ${ }^{1}$, T.M. WITHERS ${ }^{1}$, S. MANSFIELD ${ }^{1,2}$ and J. BAIN ${ }^{1}$ \\ ${ }^{1}$ Forest Biosecurity and Protection, Scion, PB 3020, Rotorua 3046, New Zea- \\ land \\ ${ }^{2}$ Current address: Faculty of Agriculture, Food and Natural Resources, \\ University of Sydney, NSW 2006, Australia
}

Corresponding author:toni.withers@scionresearch.com

\begin{abstract}
In the 1970s and 1980s two natural enemies of the eucalyptus tortoise beetle, Paropsis charybdis, an invasive pest from Australia, were established in New Zealand. Cleobora mellyi (Coccinellidae) remained localised to the Marlborough Sounds but Enoggera nassaui (Pteromalidae) showed a significant impact and spread throughout the country. A self-introduced hyperparasitoid Baeoanusia albifunicle (Encyrtidae) has recently disrupted the biological control of P. charybdis by E. nassaui. Another self-introduced parasitoid Neopolycystus insectifurax (Pteromalidae) has also appeared. As the distributions of the three parasitoids and $C$. mellyi throughout the eucalypt growing areas of New Zealand were largely unknown, historical records were reviewed and a field survey of selected areas was carried out. The three parasitoids are widely distributed, and despite some recent inundative releases of $C$. mellyi, it does not appear to have established in other geographical areas yet. The effectiveness of the biocontrol agents against $P$. charybdis will be the focus of future research.

Keywords: Paropsis charybdis, Enoggera nassaui, Cleobora mellyi, Neopolycystus insectifurax, Baeoanusia albifunicle, biological control, distribution.
\end{abstract}

\section{INTRODUCTION}

Eucalyptus remains an important exotic hardwood genus in New Zealand having been planted for woodlots, shelterbelts, shade, timber, firewood and pulp. Historically, commercial production of some of the most desirable species in the sub-genus Symphyomyrtus Section Maidenaria (after Pryor \& Johnson 1971) had to be deferred due in part to susceptibility to defoliation by the Australian eucalyptus tortoise beetle, Paropsis charybdis Stål (Chrysomelidae) (Wilcox 1980; Nicholas \& Hay 1990). This was particularly the case for E. nitens (H. Deane \& Maiden) Maiden (Lembke 1977; Nicholas \& Hay 1990), which had been recognised for its ease of establishment, early vigour, cold tolerance and potential for pulpwood and sawn timber (Wilcox 1980).

In the 1970s and 1980s four natural enemies of $P$. charybdis were released in New Zealand: Froggattimyia tillyardi Malloch (Tachinidae), Neopolycystus sp. (Pteromalidae), Enoggera nassaui (Girault) (Pteromalidae), and Cleobora mellyi Mulsant (Coccinellidae), of which the latter two established (Bain \& Kay 1989). Up until 2004, distribution of the ladybird C. mellyi was limited to areas close to the original release site in the Marlborough Sounds (Satchell 2004). The egg parasitoid E. nassaui achieved broad geographic distribution soon after its introduction. With over 100,000 adults reared and sold to forest managers throughout the country it spread quickly to provide effective control of the pest in many regions (Kay 1990). The reduction in the severity of defoliation by $P$. charybdis, and recognition of the superior pulpwood characteristics of $E$. nitens, meant this species has become the dominant plantation eucalypt in New Zealand. However, in 
spite of the action of the parasitoid, $P$. charybdis remains New Zealand's most serious eucalypt defoliator (Withers 2001).

The egg parasitoid, Neopolycystus sp., was released in New Zealand in the 1980s but failed to establish. In 2002 a related self-introduced species, $N$. insectifurax Girault, was detected in P. charybdis eggs in the Bay of Plenty (Berry 2003). The same summer an obligate hyperparasitoid of E. nassaui, Baeoanusia albifunicle Girault (Encyrtidae) was also discovered in the Bay of Plenty (Murphy 2002). Concerns were immediately raised over potential impacts on the primary parasitoid population and resulting effects on the long-term suppression of $P$. charybdis. Neopolycystus insectifurax is not susceptible to the hyperparasitoid and may play an increasingly important role in the regulation of P. charybdis with any decline in E. nassaui populations (Tribe \& Cillié 2000; Murphy 2002; Jones \& Withers 2003). The purpose of the current study was to quantify how far both self-introduced species had spread.

\section{MATERIALS AND METHODS}

A review of the biological control programme for $P$. charybdis was accomplished by searching the scientific literature and internal reports of the New Zealand Forest Research Institute Ltd (which trades as Scion). A list of all known distribution records for E. nassaui, N. insectifurax, B. albifunicle and C. mellyi was compiled from the records of the Forest Health Database, Scion. Field surveys were conducted between December 2007 and January 2008 in Northland and Gisborne regions and throughout New Zealand's South Island. These were the first directed surveys for N. insectifurax and B. albifunicle in the South Island where E. nitens plantations continue to increase.

Field surveys utilised eucalypts along roadsides and in public parks and reserves and permission was sought to access private farm forestry and plantation forestry land. Lower foliage was assessed for signs of $P$. charybdis damage before being thoroughly searched for $P$. charybdis egg batches. When foliage was not accessible from the ground but $P$. charybdis damage was apparent, pole-pruners were used to gather foliage from up to $10 \mathrm{~m}$ high. Live egg batches were maintained until $P$. charybdis larvae or parasitoids emerged and were identified to species. Remains of egg batches were also collected and assessed under a microscope to determine if they had been parasitised by E. nassaui or $N$.insectifurax based on markings on the egg shells. However, this method does not allow detection of B. albifunicle as the colouration of hyperparasitised eggs is indistinguishable from that of eggs parasitised by E. nassaui.

\section{Review of biological control programmes}

RESULTS AND DISCUSSION

Releases of the four agents introduced for the control of $P$. charybdis are summarised in Table 1. Cleobora mellyi has recently been the focus of research techniques for improved mass rearing and assessing its potential to interfere with the control of $P$. charybdis by preying on eggs parasitised by E.nassaui and N. insectifurax (S. Mansfield, unpublished data). A programme resulting in the release of over 3000 C. mellyi adults and 1350 eggs has also been instigated. Releases were made in stands of Acacia melanoxylon R.Br. at 17 sites from Northland to Rotorua in an attempt to broaden the geographical range of the beetle (Brown 2007). To date no establishments resulting from these releases have been documented.

The successful establishment of E. nassaui after the 1987-88 releases of insects sourced from Perth has been followed by the release of a Tasmanian strain (Murphy et al. 2004). This strain was recollected in Taupo (Murphy et al.2004) and future research is planned to quantify establishment and spread using predetermined molecular methods. 
TABLE 1: Releases and self-introductions of biological control agents of the defoliating beetle $P$. charybdis in New Zealand.

\begin{tabular}{|c|c|c|c|}
\hline Agent & Years: numbers released & Established & Reference \\
\hline \multirow[t]{2}{*}{$\begin{array}{l}\text { Cleobora mellyi Mulsant } \\
\text { (Coccinellidae) }\end{array}$} & 1980-1983: 9000 & $\begin{array}{c}\text { Yes, } \\
\text { Marlborough } \\
\text { Sounds }\end{array}$ & Bain et al. 1984 \\
\hline & $\begin{array}{l}\text { 2006-2007: } 1350 \text { eggs; } \\
3372 \text { adults }\end{array}$ & $?$ & Unpubl. data \\
\hline \multirow[t]{2}{*}{$\begin{array}{l}\text { Enoggera nassaui } \\
\text { (Girault) (Pteromalidae) }\end{array}$} & $\begin{array}{l}\text { 1987-1988: } 15000 \\
\text { (ex Perth) }\end{array}$ & Yes & Bain \& Kay 1989 \\
\hline & $\begin{array}{l}\text { 2000: } 6000 \text { (ex } \\
\text { Tasmania) }\end{array}$ & Yes, Taupo & Murphy et al. 2004 \\
\hline $\begin{array}{l}\text { Neopolycystus } \\
\text { insectifurax Girault }\end{array}$ & 2002: self-introduced & Yes & Berry 2003 \\
\hline (Pteromalidae) & 2003-2004: 5000 & $?$ & Unpubl. data \\
\hline $\begin{array}{l}\text { Neopolycystus sp. } \\
\text { (Pteromalidae) }\end{array}$ & 1987-1988: 7000 & No & Bain \& Kay 1989 \\
\hline $\begin{array}{l}\text { Froggattimyia tillyardi } \\
\text { Malloch (Tachinidae) }\end{array}$ & 1975: 700 & No & Bain \& Kay 1989 \\
\hline
\end{tabular}

Subsequent to the self-introductions of $N$. insectifurax and B. albifunicle in the Bay of Plenty, field monitoring of E. nitens plantations resumed in 2003. Parasitism of $P$. charybdis eggs by E. nassaui declined during the season, with approximately $40 \%$ of parasitised eggs being hyperparasitised by $B$. albifunicle. Additionally, $N$. insectifurax was recorded parasitising between $35-100 \%$ of $P$. charybdis eggs by late summer. This indicated that, while $B$. albifunicle had the potential to severely reduce the effectiveness of $E$. nassaui, the new arrival $N$. insectifurax held promise as an alternative biological control agent (Jones \& Withers 2003). Inundative releases of $N$. insectifurax were made in the Bay of Plenty in 2003-2004 but failed to improve parasitism rates in the following season (S. Mansfield et al., unpubl. data). As a result the inundative release programme and monitoring ceased.

\section{Geographical and database survey}

In the discussion that follows the regions of New Zealand as defined by Crosby et al. (1998) are used. Parasitised egg batches were collected from 21 sites between Picton (SD) and Roxburgh (CO) as well as Kerikeri (ND) and Wairoa (GB) (Figs 1a, 1b \& 1c). Enoggera nassaui has now been recovered from 20 regions in total, seven of which were identified in this survey (Fig 1a). Regions where E. nassaui has not been recorded represent those we believe have not yet been adequately surveyed to coincide with host and parasitoid phenology. Enoggera nassaui is expected to be present in all eucalypt growing areas of the country.

Both $N$. insectifurax and B. albifunicle were recovered from the South Island for the first time during this survey. The hyperparasitoid, B. albifunicle, previously recorded only from three North Island regions, Bay of Plenty, Taupo and Coromandel (BP, TO, CL) was located in ND, GB and six South Island locations as far south as Roxburgh (Fig. 1c). In addition to previous records from BP and CL, N. insectifurax was also located for the first time in ND, GB, North Canterbury, Marlborough and Kaikoura (NC, MB, KA). Photographs of eggs parasitised by $N$. insectifurax had been taken in ND in January 2005, but the first adult specimens for identification were collected from the region during the current survey. 


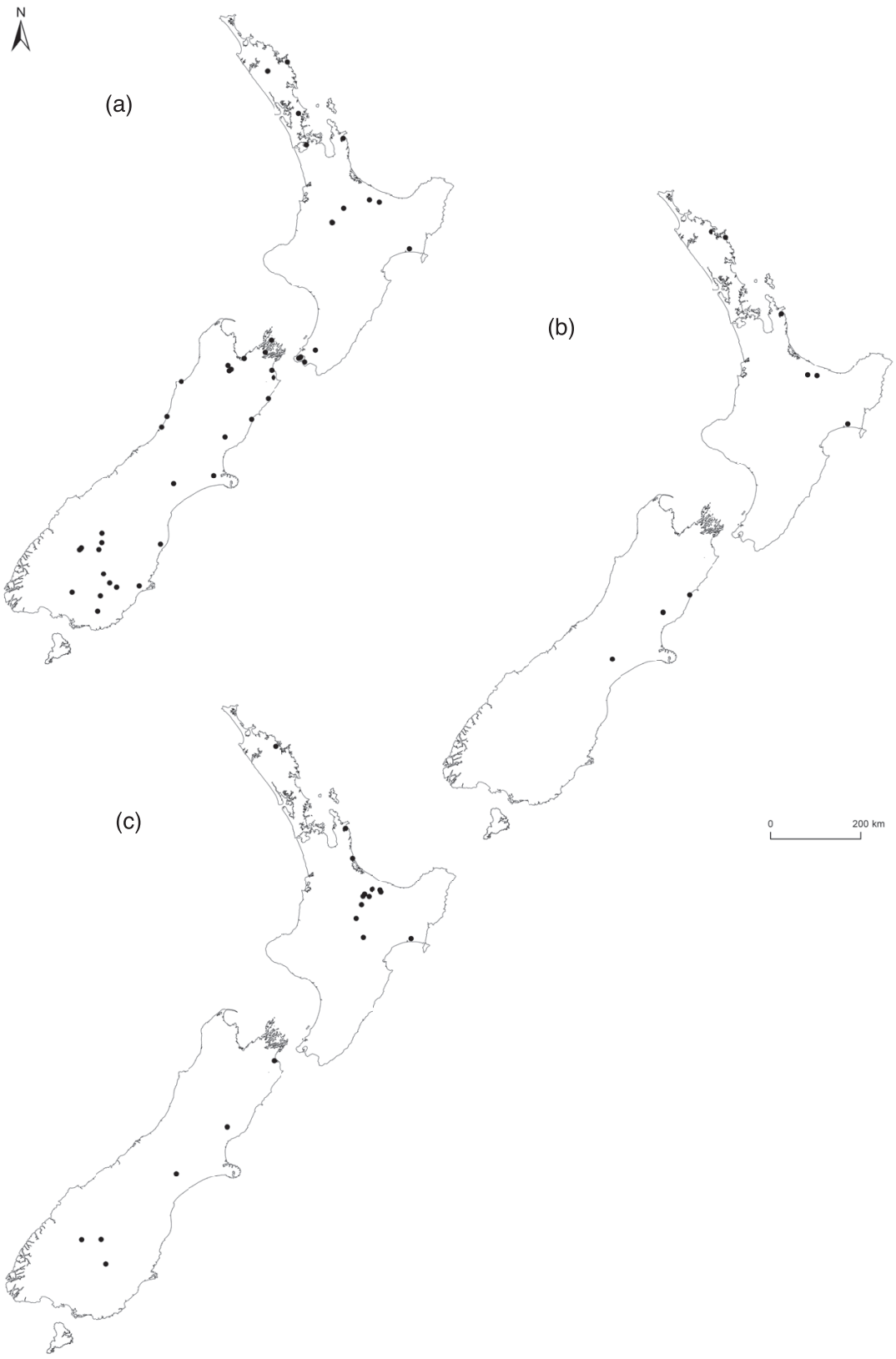

FIGURE 1: Current distribution in New Zealand of (a) E. nassaui, (b) $N$. insectifurax and (c) B. albifunicle. 
Cleobora mellyi was collected only in Picton, which is still close to the original establishment site and within the Marlborough Sounds region (SD).

As all three parasitoid species appear to have established in Northland, with its warm wet climate, as well as in cooler central North Island areas and the dry central South Island with its hot summers and cold winters, it is unlikely their distrubutions will be climate-limited in New Zealand. Although a complete data set is not yet available, both $N$. insectifurax and B. albifunicle are also expected to establish wherever their host is present, with the possible exception of Southland. Extensive collections of $P$. charybdis eggs parasitised by $E$. nassaui have been made in Southland over the last 3 years, but to date neither $N$. insectifurax nor $B$. albifunicle have been detected. This could be a climate-related effect ( $N$. insectifurax has higher temperature thresholds than $E$. nassaui in the laboratory, S. Mansfield, unpubl. data), or the two speices may have simply not yet reached this region.

\section{CONCLUSIONS}

Three biological control agents of the pest beetle $P$. charybdis are currently established in New Zealand. Enoggera nassaui, the primary control agent of $P$. charybdis, is well established throughout eucalypt growing regions of the country and a second, potentially more cold tolerant strain, has been introduced. Incursions of two additional parasitoid species appear to be altering the seasonal patterns of $P$. charybdis control but it is unlikely that a new equilibrium has yet been reached. If $B$. albifunicle is reducing the abundance of $E$. nassaui one might expect to witness increasing defoliation from the spring generation of $P$. charybdis, which may obtain even greater freedom from parasitism by E. nassaui. In Australia $N$. insectifurax tends to be the more dominant parasitoid when it occurs in sympatry with E. nassaui and B. albifunicle (Cumpston 1939). In the central North Island there is some evidence that $N$. insectifurax might be beginning to dominate over $E$. nassaui during the second $P$. charybdis generation in late summer, presumably due to the influence of the hyperparasitoid. Consequently, $C$. mellyi may be a more promising control agent for the spring generation of $P$. charybdis. A trial within plantation trees in Tasmania revealed a significant peak of $C$. mellyi numbers in early November (springtime) (Bashford 1999). Unfortunately to date, C. mellyi has been recovered from only one region but attempts are being made to broaden its geographical distribution. However, this beetle has the potential to alter food web dynamics and impact upon non-target species in unknown ways. This is because it is able to feed on multiple prey species and psyllids are an essential food for reproduction (Bain et al. 1984). Psyllid species richness on Eucalyptus and Acacia has increased in recent years (Withers 2001).

A better understanding of how these species interact in New Zealand is required and it may be several more years before the full extent of such interactions on $P$. charybdis control are known. To understand whether $B$. albifunicle is seriously impeding the control provided by $E$. nassaui, if $N$. insectifurax is capable of compensating for this, or if $C$. mellyi has established in the North Island, intensive monitoring of the seasonal variations in parasitism and predation by each species is needed.

\section{ACKNOWLEDGMENTS}

This research was funded by the Foundation for Research, Science and Technology (Contract No.CO4X0302) and the Forest Biosecurity Research Council to Scion, and supported through Tara Murray's PhD research by Lincoln University, the New Zealand Plant Protection Society Inc. Research Scholarship, MacMillan Brown Agricultural Research Scholarship and the Robert C. Bruce Trust Research Grant. Thanks to the New Zealand Farm Forestry Association (NZFFA) and the Acacia melanoxylon Interest Group Organisation (AMIGO), as well as Wenita, P F Olsen, Timberlands and BlakelyPacific for allowing access to their properties. Many thanks also to Richard Thum of SPS Biosecurity, and to Dean Satchell who sent in parasitised egg batches for identification. Dean supplied $C$. mellyi release data that was funded by AMIGO and Ministry of Agriculture and Forestry Sustainable Farming Fund. 


\section{REFERENCES}

Bain J, Kay MK 1989. Paropsis charybdis Stål, eucalyptus tortoise beetle (Coleoptera: Chrysomelidae) In: Cameron PJ, Hill RL, Bain J, Thomas WP ed. A review of biological control of invertebrate pests and weeds in New Zealand 1874-1987. CAB International Technical Communication No. 10 and DSIR, Oxon, UK. Pp. 281-287.

Bain J, Singh P, Ashby MD, van Boven RJ 1984. Laboratory rearing of the predatory coccinellid Cleobora mellyi (Coleoptera: Coccinellidae) for the biological control of Paropsis charybdis (Col: Chrysomelidae) in New Zealand. Entomophaga 29(2): 237-244.

Bashford R 1999. Predation by ladybird beetles (coccinellids) on immature stages of the Eucalyptus leaf beetle Chrysophtharta bimaculata (Olivier). Tasforests 11: 77-86.

Berry JA 2003. Neopolycystus insectifurax Girault (Hymenoptera: Pteromalidae) is established in New Zealand, but how did it get here? New Zealand Entomologist 26:113-114.

Brown I 2007. L06-002 Final Report. http://www.maf.govt.nz/sff/about-projects/search/ L06-002/final-report.htm\#P4_1273 [accessed 10 April 2008].

Crosby TK, Dugdale JS, Watt JC 1998. Area codes for recording specimens' localities in the New Zealand subregion. New Zealand Journal of Zoology 25: 175-183.

Cumpston DM 1939. Observations on the bionomics and morphology of seven species of the tribe Paropsini (Chrysomelidae). Proceedings of the Linnean Society of New South Wales 64: 353-366.

Jones DC, Withers TM 2003. The seasonal abundance of the newly established parasitoid complex of the Eucalyptus tortoise beetle (Paropsis charybdis). New Zealand Plant Protection 56: 51-55.

Kay MK1990. Success with biological control of the eucalyptus tortoise beetle, Paropsis charybdis. What's New in Forest Research, No. 184. 4 pp.

Lembke CA 1977. N.Z. Forest Products Limited turns to eucalypt. Australian Forest Industries Journal 43(7): 26-31.

Murphy B 2002. New insect threatens control of Eucalyptus tortoise beetle. Forest Health News 117. 2 pp.

Murphy BD, Kay MK, Allen GR 2004. Detection of a Tasmanian strain of the biological control agent Enoggera nassaui Girault (Hymenoptera: Pteromalidae) using mitochondrial COI. New Zealand Plant Protection 57: 252-256.

Nicholas I, Hay E 1990. Selection of special-purpose timbers: effect of pests and diseases. New Zealand Journal of Forestry Science 20(3): 279-289.

Pryor LD, Johnson LAS 1971. A classification of the eucalypts. The Australian National University. $102 \mathrm{pp}$

Satchell D 2004. Cleobora alive and well in the South Island. Forest Health News 140. $2 \mathrm{pp}$.

Tribe GD, Cillié JJ 2000. Biological control of Eucalyptus-defoliating Australian tortoise beetle Trachymela tincticollis (Blackburn) (Chrysomelidae: Chrysomelinae: Chrysomelini: Paropsina) in South Africa by the egg parasitoid Enoggera reticulata Naumann (Hymenoptera: Pteromelidae: Asaphinae). African Entomology 8(1): 15-22.

Wilcox MD 1980. Genetic improvement of eucalypts in New Zealand. New Zealand Journal of Forestry Science 10(2): 343-359.

Withers TM 2001. Colonization of Eucalyptus in New Zealand by Australian insects. Austral Ecology 26: 467-476. 